\title{
A Comparative Study of Spinel ZnFe204 Ferrites Obtained via a Hydrothermal and a Ceramic Route: Structural and Magnetic Properties
}

\section{Xuesong Zhu}

Anhui University of Technology

\section{Chunxiang Cao}

Anhui University of Technology

\section{Shubing Su}

Ningbo University of Technology

A.L.Xia ( $\nabla$ alxia@126.com)

Anhui University of Technology https://orcid.org/0000-0002-5223-519X

Huiyan Zhang

Anhui University of Technology

Hailing Li

Anhui University of Technology

Zhiyuan Liu

Anhui University of Technology

Chuangui Jin

Anhui University of Technology

\section{Research Article}

Keywords: Spinel, ZnFe2O4 ferrite, hydrothermal method, magnetic properties

Posted Date: August 26th, 2020

DOI: https://doi.org/10.21203/rs.3.rs-64825/v1

License: (1) (1) This work is licensed under a Creative Commons Attribution 4.0 International License.

Read Full License

Version of Record: A version of this preprint was published at Ceramics International on June 1st, 2021. See the published version at https://doi.org/10.1016/j.ceramint.2021.02.077. 


\section{A comparative study of spinel $\mathrm{ZnFe}_{2} \mathrm{O}_{4}$ ferrites obtained via a hydrothermal and a ceramic route: structural and magnetic properties}

Xuesong Zhu ${ }^{1}$, Chunxiang $\mathrm{Cao}^{2}$, Shubing $\mathrm{Su}^{3}$, Ailin Xia ${ }^{1}{ }^{*}$, Huiyan $\mathrm{Zhang}^{1}$, Hailing $\mathrm{Li}^{1}$, Zhiyuan Liu $^{1}$, Chuangui $\operatorname{Jin}^{1}{ }^{1} *$

1 School of Materials Science and Engineering, Anhui University of Technology, Maanshan 243002, China

2 Analysis and Testing Central Facility, Anhui University of Technology, Maanshan 243002, China

3 School of Electronic and Information Engineering, Ningbo University of Technology, Ningbo 315016, China

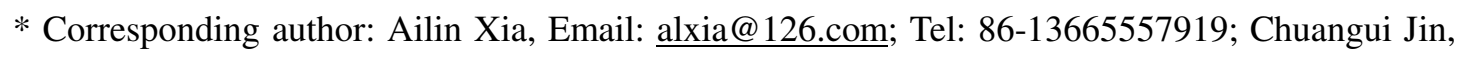
Email: jcg@ahut.edu.cn 


\begin{abstract}
The spinel $\mathrm{ZnFe}_{2} \mathrm{O}_{4}$ specimens were obtained via a hydrothermal and a ceramic method, respectively, and their structural and magnetic properties were comparatively studied. It was found that all the specimens exhibited a single-phase and mixed spinel structure. The magnetism of specimens synthesized via the hydrothermal method is obviously greater than that of specimen prepared via the ceramic method. This can be ascribed to the occupancy of $\mathrm{Fe}$ ions resulted from the loss of $\mathrm{Zn}$ during the hydrothermal process.
\end{abstract}

\title{
Key words
}

Spinel; $\mathrm{ZnFe}_{2} \mathrm{O}_{4}$ ferrite; hydrothermal method; magnetic properties 


\section{Introduction}

The spinel structure with a formula of $\mathrm{AB}_{2} \mathrm{O}_{4}$ is widely studied and used in the fields of electronics, magnetism, catalyst, energy storage and so on [1-8]. Generally, A denotes the divalent metal ions, such as $\mathrm{Mg}^{2+}, \mathrm{Fe}^{2+}, \mathrm{Co}^{2+}, \mathrm{Ni}^{2+}, \mathrm{Mn}^{2+}$ and $\mathrm{Zn}^{2+}$, and $\mathrm{B}$ denotes the trivalent metal ions, such as $\mathrm{Al}^{3+}, \mathrm{Fe}^{3+}, \mathrm{Co}^{3+}$ and $\mathrm{Cr}^{3+}$. Spinel ferrites $\left(\mathrm{AFe}_{2} \mathrm{O}_{4}\right)$ are usually used as the magnetically soft materials, such as $\mathrm{MgFe}_{2} \mathrm{O}_{4}[6]$, $\mathrm{MnFe}_{2} \mathrm{O}_{4}[7], \mathrm{NiFe}_{2} \mathrm{O}_{4}[8]$ and so on. Their magnetic properties are related to the site occupancy of cations. There are 8 and 16 occupied tetrahedral A sites and octahedral B sites in a spinel unit cell of 32 oxygen ions, respectively. Different cation distribution will result in different magnetic properties due to the different superexchange interaction of A-O-B and B-O-B [9].

Spinel $\mathrm{ZnFe}_{2} \mathrm{O}_{4}(\mathrm{ZFO})$ ferrite is widely studied as a kind of potential catalytic or anodic material [10-13]. Theoretically, ZFO is a typical normal spinel ferrite with a cation distribution in lattice sites as the following:

$$
\left(\mathrm{Zn}^{2+}\right)\left[{ }^{\uparrow} \mathrm{Fe}^{3+\downarrow} \mathrm{Fe}^{3+}\right] \mathrm{O}_{4}
$$

A $\quad B$

Where $\mathrm{Zn}^{2+}$ in $\mathrm{A}$ site is nonmagnetic, and the magnetic moment of two $\mathrm{Fe}^{3+}$ ions in $\mathrm{B}$ sites presents an antiparallel arrangement as described by the Yafet-Kittle configuration[14, 15], which results in the zero magnetic moment in ZFO. Therefore, if partial $\mathrm{Fe}^{3+}$ ions in $\mathrm{B}$ sites are forced to locate in A sites, the magnetism in ZFO could transform from antiferromagnetism to ferrimagnetism. This is instructive to the study of magnetism in spinel structures, and consequently the magnetism in ZFO also aroused the interest of some researchers [16-18]. It has been proved that the sintering 
temperature should be a key factor for the site occupancy of $\mathrm{Fe}^{3+}[16,17]$. In this study, we prepared the ZFO specimens via a hydrothermal method and a traditional ceramic method, respectively, and proved that the $\mathrm{Zn}$-deficiency can also cause the transition of magnetism from antiferromagnetism to ferrimagnetism in ZFO.

\section{Experimental}

2.1 Synthesis of ZFO via a hydrothermal route (HZFO)

A common hydrothermal route was used to prepare ZFO specimens with a nominal composition of $\mathrm{ZnFe}_{2} \mathrm{O}_{4}$. All the chemical reagents used were analytically pure without further treatment.

First, the mixed $\mathrm{Fe}\left(\mathrm{NO}_{3}\right)_{3} \cdot 9 \mathrm{H}_{2} \mathrm{O}$ and $\mathrm{Zn}\left(\mathrm{NO}_{3}\right)_{2} \cdot 6 \mathrm{H}_{2} \mathrm{O}$ with the $\mathrm{Fe} / \mathrm{Zn}$ atomic ratio $\left(R_{a}\right)$ of 2:1 were uniformly dissolved in deionized water and then coprecipitated by using the $\mathrm{NaOH}$ solution with the $\mathrm{OH}^{-} / \mathrm{NO}_{3}{ }^{-}$molar ratio of $3: 1[19]$. Then, the precipitates and aqueous solution were moved to a Teflon liner and hydrothermally reacted at a temperature $\left(T_{h}\right)$ of $160^{\circ} \mathrm{C}, 180^{\circ} \mathrm{C}$ and $200^{\circ} \mathrm{C}$, respectively. Finally, the obtained powders after the hydrothermal reaction were used as the specimens after washing by deionized water and absolute ethylalcohol for 3 and 2 times, respectively. For convenience, the specimens obtained with a $T_{h}$ of $160^{\circ} \mathrm{C}, 180^{\circ} \mathrm{C}$ and $200^{\circ} \mathrm{C}$ were denoted as HZFO-160, HZFO-180 and HZFO-200, respectively.

\subsection{Preparation of ZFO via a ceramic route (CZFO)}

First, analytically pure $\mathrm{ZnO}$ and $\mathrm{Fe}_{2} \mathrm{O}_{3}$ powders were mixed uniformly with the $R_{a}$ of $2: 1$. Then, the mixed powders were roughly pressed into circular tablets with a 
diameter of about $10 \mathrm{~mm}$. Finally, these circular tablets were sintered at $750^{\circ} \mathrm{C}$ for 2 hours to be used as the CZFO-750 specimen in this study.

\subsection{Characterization}

The phase composition of specimens were identified and confirmed by using an $\mathrm{X}$-ray diffractometer (XRD, Rigaku D/max-2550V/PC) using $\mathrm{Cu} \mathrm{K} \alpha$ radiation and a Fourier transformed infrared spectrometer (FTIR, Nicolet 6700), respectively. The content, distribution and chemical state of metal elements were investigated by using an inductively coupled plasma-atomic emission spectrometer (ICP, Agilent 720), an energy dispersive spectrometer (EDS, Oxford X-Max 20) and an X-ray photoelectron spectroscope (XPS, Escalab 250Xi), respectively. The micrographs were obtained by using a transmission electron microscope (TEM, Thermo Scientific Talos F2100X) and a field emission scanning electron microscope (FESEM, Zeiss omega 500). The Room-temperature (RT) magnetic properties were obtained through the magnetic hysteresis loops measured on a vibrating sample magnetometer (VSM, Quantum

Design Versalab) with the maximum external field of about $2388 \mathrm{kA} \cdot \mathrm{m}^{-1}(30,000$ Oe).

\section{Results and discussion}

\subsection{HZFO synthesized via a hydrothermal route}

In this study, ZFO specimens were prepared using the Fe/Zn atomic ratio of 2:1, a stoichiometric composition, in the starting materials. Fig. 1 shows the XRD patterns of as-synthesized HZFO specimens with different $T_{h}$. Typical peak information from 
ZFO without any other impurity peaks is revealed in the three XRD patterns, indicating their single-phase spinel ZFO structure (PDF\#22-1012) in the space group Fd-3m.

The results of FTIR can help to confirm the formation of spinel structure and give some information of chemical bond. Fig. 2 gives the FTIR spectra of HZFO specimens. The characteristic absorption bands at around $450 \mathrm{~cm}^{-1}$ and $575 \mathrm{~cm}^{-1}$ can be ascribed to the bending or stretching vibrations of $\mathrm{A}-\mathrm{O}_{4}$ and $\mathrm{B}-\mathrm{O}_{6}$ in spinels, which is consistent with the results in previous reports $[10,20]$, suggesting the formation of spinel structure.

Using the XRD patterns in Fig. 1 and the famous Scherrer equation [16], the average crystallite size $(D)$ was calculated to be $7.3,7.4$ and $8.2 \mathrm{~nm}$ for specimens HZFO-160, HZFO-180 and HZFO-200, respectively. It can be concluded that the crystallites grew faster at a higher $T_{h}$. This can be confirmed by the typical FESEM and TEM images of HZFO specimens shown in Fig. 3 and Fig. 4, respectively. Seen from Fig. 3, the HZFO specimens consist of many aggregated small particles. When seen from Fig. 4, all the HZFO specimens are composed of small nanoparticles mainly less than $10 \mathrm{~nm}$, which is consistent with the values of $D$ obtained using the Scherrer equation. The obvious increase of $D$ in HZFO-200 (Fig. 4c) due to the higher $T_{h}$ can also be found if compared with that of HZFO-160 (Fig. 4a) and HZFO-180 (Fig. 4b). What should be pointed out is that as shown in Fig. 3c, the specimen synthesized at $T_{h}=200^{\circ} \mathrm{C}(\mathrm{HZFO}-200)$ exhibits a more compact aggregation, which may be due to the higher saturation magnetization $\left(M_{\mathrm{s}}\right)$ discussed later. 
The typical EDS mapping images of a selected area in the typical specimen HZFO-200 are given in Fig. 5. For the metal elements, only count from Zn and Fe can be found in the measured area. Moreover, the count is uniformly distributed in the mapping images, implying that the compositional distributions of $\mathrm{Zn}$ and $\mathrm{Fe}$ in the specimen are uniform.

\subsection{CZFO-750 prepared via a ceramic route}

In order to compare the magnetic properties with HZFO, the CZFO-750 specimen was prepared via a ceramic route. Fig. 6a shows the XRD pattern of CZFO-750. The pattern also reveals the typical peak information of spinel ZFO (PDF\#22-1012) in the space group $F d-3 m$. However, the peaks became visibly narrower compared with those in Fig. 1. This can be ascribed to the crystallite growth after sintering at the high temperature of $750^{\circ} \mathrm{C}$. Note that the typical FESEM image of CZFO-750 illustrated in Fig. 6b confirms this result. Most of the crystallites grew up to a size of about $200 \mathrm{~nm}$, far beyond the limited size of $100 \mathrm{~nm}$ that can be calculated by using the Scherrer equation. Fig. 6c gives the typical EDS mapping images in the selected area of CZFO-750 to prove the uniformity of metal elements. Obviously, the count from both $\mathrm{Zn}$ and Fe are uniformly distributed in the selected area just like that in Fig. 5, also indicating the uniformity of chemical composition in CZFO-750.

\subsection{Magnetic properties}


The magnetism of spinels is associated with the difference of magnetic moments between $\mathrm{A}$ and $\mathrm{B}$ sites [9]. According to the cation distribution in lattice sites described above for a normal spinel ferrite, the magnetic moment in a ZFO molecular formula can be calculated as:

$$
\left|M_{\mathrm{A}^{-}}\left(M_{\mathrm{B} \uparrow}-M_{\mathrm{B} \downarrow} \downarrow\right)\right|=\left|0 \mu_{B^{-}}\left(5 \mu_{\mathrm{B}}-5 \mu_{\mathrm{B}}\right)\right|=0 \mu_{B}
$$

Where $M_{\mathrm{A}}$ and $M_{\mathrm{B}}$ present the magnetic moment in $\mathrm{A}$ and $\mathrm{B}$ sites, respectively. Therefore, generally, the normal spinel ferrite should exhibit zero magnetic moment.

The RT magnetic hysteresis loops of HZFO specimens are illustrated in Fig.7. According to the Ref. [18] combined with $D$ obtained from the results of XRD and TEM, the negligible coercivity $\left(H_{\mathrm{c}}\right)$ and remanent magnetism $\left(M_{\mathrm{r}}\right)$ together with unsaturated magnetization at relatively high magnetic field could help to confirm the superparamagnetism of our HZFO nanoparticles. However, the superparamagnetism of HZFO nanoparticles is not the emphasis in this study, and will be discussed in another report systematically. Therefore, the dependence of magnetization $(M)$ on the temperature $(T)$ under the zero field cooling (ZFC) and field cooling (FC) that can confirm the existence of superparamagnetism is not given here.

Seen from Fig. 7, for the sake of discussion, the $M$ at the maximum external field of $\pm 2388 \mathrm{kA} \cdot \mathrm{m}^{-1}(30,000 \mathrm{Oe})$ was considered as the $M_{\mathrm{s}}$. The calculated $M_{\mathrm{s}}$ of HZFO-160, HZFO-180 and HZFO-200 is 15.05, 22.19 and $24.56 \mathrm{emu} / \mathrm{g}$, respectively, exhibiting a value much higher than zero. As is well-known, $\mathrm{Zn}(\mathrm{OH})_{2}$ is amphoteric, which can also be dissolved in the alkaline solution [21]. Therefore, for a hydrothermal method, $\mathrm{Zn}^{2+}$ is easy to lose in the aqueous solution during the synthesis. 
As described above, theoretically, the molecular magnetic moment of normal ZFO should be zero. However, the Zn-deficiency in A sites could result in the occupancy of partial Fe ions in A sites, and consequently form the mixed spinel ZFO. According to the Yafet-Kittle configuration for spinels [15], this was sure to result in that the magnetic moment in A and B sites could not cancel each other out, which would enhance the molecular magnetic moment. As for the increasing trend of $M_{\mathrm{s}}$ with the increasing $T_{\mathrm{h}}$, it should deal with the occupancy of $\mathrm{Fe}$ as well as the better crystallinity of specimens at higher $T_{\mathrm{h}}[22]$.

In order to prove the Zn-deficiency in HZFO specimens, the ICP results of both HZFO and CZFO-750 specimens are listed in Table 1. It can be seen that for HZFO specimens, the $R_{a}$ is obviously higher than 2 , the nominal composition in the starting materials. This is obviously related with the loss of $\mathrm{Zn}$ during the hydrothermal synthesis process as described above. However, the $R_{\mathrm{a}}$ of CZFO-750 is 1.984 , which is very close to 2 . As is well-known, $\mathrm{Zn}^{2+}$ ions are not easy to lose during a ceramic process.

The RT magnetic hysteresis loop of CZFO-750 is also given in Fig. 7. It can be seen that the $M$ was not saturated at the maximum external field of about 2388 $\mathrm{kA} \cdot \mathrm{m}^{-1}(30,000 \mathrm{Oe})$ and was nearly proportional to the external magnetic field. Moreover, the $M$ at the maximum external field of $\pm 2388 \mathrm{kA} \cdot \mathrm{m}^{-1}$ is lower than 4 emu/g, a very small value compared with that of the HZFO specimens.

In order to further interpret the difference in magnetism between HZFO and CZFO, the XPS spectra of two typical specimens HZFO-200 and CZFO-750 were 
presented in Fig. 8 to show more information of ion occupancy in A and B sites, and the corresponding binding energies (BEs) are listed in Table 2. Seen from the Fig. 8 (a), the BEs of Zn 2p3/2 and Zn 2p1/2 in HZFO-200 is about 1021.06 and $1044.10 \mathrm{eV}$, respectively, just the typical Bes value of $\mathrm{Zn}^{2+}$ ions. However, both the $\mathrm{Zn} 2 \mathrm{p} 3 / 2$ and $2 \mathrm{p} 1 / 2$ peaks can be fitted to 2 peaks. The peaks at $1020.99,1044.11 \mathrm{eV}$ and 1021.68, $1045.04 \mathrm{eV}$ can be ascribed to the tetrahedral (tet) A sites and the octahedral (oct) B sites, respectively. Generally, $\mathrm{Zn}^{2+}$ ions strongly prefer to occupy A sites, while they were also reported to occupy B sites $[16,17]$. The similar results can be seen in Fig. 8 (b) of CZFO-750. Fig. 8 (c-f) shows the XPS spectra of Fe 2p, 3p and the corresponding satellite (sat) peaks. For the HZFO and CZFO specimens, all the Fe $2 p$ and $3 p$ peaks can be fitted to 2 peaks resulted from the $\mathrm{Fe}^{3+}$ ions in tetrahedral sites and octahedral sites (as shown in Table 2), respectively, which implies that $\mathrm{Fe}^{3+}$ ions occupy A sites as well as B sites. This is similar to the results in the previous reports $[16,17,23]$.

According to the results of XPS, both the HZFO and CZFO specimens formed the mixed spinel structure like $\left(\mathrm{Zn}_{1-x}^{2+} \mathrm{Fe}_{x}^{3+}\right)\left[\mathrm{Fe}_{2-x}^{3+} \mathrm{Zn}_{x}^{2+}\right] \mathrm{O}_{4}$ during the preparation process. Consequently, the difference in magnetism should be ascribed to the arrangement of magnetic moments. According to the Yafet-Kittle configuration [15], for the $\mathrm{Zn}$-deficient HZFO specimens whose $R_{\mathrm{a}}$ is larger than 2, in order to keep the balance of chemical valence, the specimens could prefer to form the magnetic structure of $\left(\mathrm{Zn}_{1-x}^{2+\downarrow} \mathrm{Fe}_{x}^{3+}\right)\left[{ }^{\uparrow} \mathrm{Fe}_{2-x+\delta}^{3+} \mathrm{Zn}_{x}^{2+} \square_{3 \delta}^{-}\right] \mathrm{O}_{4}$, where $\square$ presents the vacancy with negative charge. However, for the CZFO specimen whose $R_{\mathrm{a}}$ is slightly smaller than 2 , 
the specimen could prefer to form the magnetic structure of $\left.\left(\mathrm{Zn}_{1-x}^{2+\downarrow} \mathrm{Fe}_{x}^{3+}\right){ }^{\uparrow} \mathrm{Fe}_{x}^{3+\uparrow} \mathrm{Fe}_{1-x}^{3+\downarrow} \mathrm{Fe}_{1-x}^{3+} \mathrm{Zn}_{x+\delta}^{2+}\right] \mathrm{O}_{4}$. Similar to equation (1), theoretically, the molecular magnetic moment of the former is markedly larger than the latter.

From the discussion of magnetism, it is obvious that the Zn-deficiency affected the occupancy of Fe and the magnetism in ZFO.

\section{Conclusions}

Single-phase $\mathrm{ZnFe}_{2} \mathrm{O}_{4}$ specimens were obtained via a hydrothermal and a traditional ceramic method, respectively. The magnetization at assigned magnetic fields of the former specimens is obviously greater than that of the latter specimen. This can be ascribed to the loss of $\mathrm{Zn}$ ions in the aqueous solution during the hydrothermal process, which should result in the occupancy of some Fe ions in A sites of $\mathrm{ZnFe}_{2} \mathrm{O}_{4}$ to form the mixed spinel structure. Consequently, the magnetism could be tuned by the $\mathrm{Zn}$-deficiency in the specimens synthesized via a hydrothermal route.

\section{Acknowledgement}

This study was financially supported by the National Natural Science Foundation of China under Grant no. 51772004.

\section{References}

[1] Mao AQ, Xiang HZ, Zhang ZG, Kuramoto K, Zhang H, Jia Y. A new class of spinel high-entropy oxides with controllable magnetic properties. J Magn Magn 
Mater 2020, 497: 165884.

[2] Luchechko A, Shpotyuk Y, Kravets O, Zaremba O, Szmuc K, Cebulski J, Ingram A, Golovchak R, Shpotyuk O. Microstructure and luminescent properties of $\mathrm{Eu}^{3+}$-activated $\mathrm{MgGa}_{2} \mathrm{O}_{4}: \mathrm{Mn}^{2+}$ ceramic phosphors. J Adv Ceram 2020, 9: 432-443.

[3] Sickafus KE, Wills JM, Grimes NW. Structure of spinel. J Am Ceram Soc 1999, 82: $3279-3292$.

[4] Tangcharoen T, T-Thienprasert J, Kongmark C. Effect of calcination temperature on structural and optical properties of $\mathrm{MAl}_{2} \mathrm{O}_{4}(\mathrm{M}=\mathrm{Ni}, \mathrm{Cu}, \mathrm{Zn})$ aluminate spinel nanoparticles. J Adv Ceram 2019, 8: 352-366.

[5] Ferg E, Gummow RJ, de Kock A, Thackeray MM. Spinel anodes for lithium - ion batteries. J Electrochem Soc 1994, 141: L147-150.

[6] Ade R, Chen YS, Huang CH, Lin JG. Large magnetic anisotropy in highly strained epitaxial $\mathrm{MgFe}_{2} \mathrm{O}_{4}$ thin films. J Appl Phys 2020, 127: 113904.

[7] Islam R, Borah JP. Ab initio study of electronic structure and enhancement of magnetocrystalline anisotropy in $\mathrm{MnFe}_{2} \mathrm{O}_{4}$ for permanent magnet application. J Magn Magn Mater 2020, 499: 166268.

[8] Azadmanjiri J, Ebrahimi SAS, Salehani HK. Magnetic properties of nanosize $\mathrm{NiFe}_{2} \mathrm{O}_{4}$ particles synthesized by sol-gel auto combustion method. Ceram Int 2007, 33: $1623-1625$.

[9] Goldman A. Modern ferrite technology ( $2^{\text {nd }}$ Ed.). Springer Science + Business Media, New York, 2006.

[10] Qiao H, Li RR, Yu YT, Xia ZK, Wang LJ, Wei QF, Chen K, Qiao QQ. 
Fabrication of PANI-coated $\mathrm{ZnFe}_{2} \mathrm{O}_{4}$ nanofibers with enhanced electrochemical performance for energy storage. Electrochim Acta 2018, 273: 282-288.

[11] Zhao W, Liang C, Wang BB, Xing ST. Enhanced photocatalytic and fenton-like performance of $\mathrm{CuO}_{x}$-decorated $\mathrm{ZnFe}_{2} \mathrm{O}_{4}$. ACS Appl Mater Interfaces 2017, 9: 41927-41936.

[12] Liang PL, Yuan LY, Deng H, Wang XC, Wang L, Li ZJ, Luo SZ, Shi WQ. Photocatalytic reduction of uranium(VI) by magnetic $\mathrm{ZnFe}_{2} \mathrm{O}_{4}$ under visible light. Appl Catal B: Environ 2020, 267: 118688.

[13] Qu Y, Zhang D, Wang X, Qiu HL, Zhang T, Zhang M, Tian G, Yue HJ, Feng SH, Chen G. Porous $\mathrm{ZnFe}_{2} \mathrm{O}_{4}$ nanospheres as anode materials for $\mathrm{Li}$-ion battery with high performance. J Alloy Compd 2017, 721: 697-704.

[14] Xia AL, Liu SK, Jin CG, Chen L, Lv YH. Hydrothermal $\mathrm{Mg}_{1-x} \mathrm{Zn}_{x} \mathrm{Fe}_{2} \mathrm{O}_{4}$ spinel ferrites: Phase formation and mechanism of saturation magnetization. Mater Lett 2013, 105: 199-201.

[15] Yafet Y, Kittel C. Antiferromagnetic arrangements in ferrites. Phys Rev 1952, 87: 290-294.

[16] Tehranian P, Shokuhfar A, Bakhshi H. Tuning the magnetic properties of $\mathrm{ZnFe}_{2} \mathrm{O}_{4}$ nanoparticles through partial doping and annealing. J Supercond Nov Magn 2019, 32: 1013-1025.

[17] Q Yuan, Pan LL, Liu R, Wang JM, Liao ZZ, Qin LL, Bi J, Gao DJ, Wu JT. Cation distribution and magnetism in quenched $\mathrm{ZnFe}_{2} \mathrm{O}_{4}$. J Electron Mater 2018, 47: $3608-3614$ 
[18] Bini M, Tondo C, Capsoni D, Mozzati MC, Albini B, Galinetto P. Superparamagnetic $\mathrm{ZnFe}_{2} \mathrm{O}_{4}$ nanoparticles: The effect of $\mathrm{Ca}$ and $\mathrm{Gd}$ doping. Mater Chem Phys 2018, 204: 72-82.

[19] Xia AL, Zuo CH, Chen L, Jin CG, Lv YH. Hexagonal $\mathrm{SrFe}_{12} \mathrm{O}_{19}$ ferrites: Hydrothermal synthesis and their sintering properties. J Magn Magn Mater 2013, 332: $186-191$.

[20] Xia AL, Ren SZ, Lin JS, Ma Y, Xu C, Li JL, Jin CG, Liu XG. Magnetic properties of sintered $\mathrm{SrFe}_{12} \mathrm{O}_{19}-\mathrm{CoFe}_{2} \mathrm{O}_{4}$ nanocomposites with exchange coupling. $J$ Alloy Compd 2015, 653: 108-116.

[21] Xia AL, Jin CG, Du DX, Zhu GH. Comparative study of structural and magnetic properties of $\mathrm{NiZnCu}$ ferrite powders prepared via chemical coprecipitation method with different coprecipitators. J Magn Magn Mater 2011, 323: 1682-1685.

[22] Nairan A, Khan M, Khan U, Iqbal M, Riaz S, Naseem S. Temperature-dependent magnetic response of antiferromagnetic doping in cobalt ferrite nanostructures. Nanomaterials 2016, 6: 73.

[23] Yamashita T, Hayes P. Analysis of XPS spectra of $\mathrm{Fe}^{2+}$ and $\mathrm{Fe}^{3+}$ ions in oxide materials. Appl Surf Sci 2008, 254: 2441-2449. 



\section{Figure Captions}

Fig. 1 XRD patterns of HZFO specimens obtained at different hydrothermal temperatures $T_{h}$.

Fig. 2 FTIR spectra of HZFO specimens obtained at different hydrothermal temperatures $T_{h}$.

Fig. 3 Typical FESEM images of HZFO specimens obtained at different hydrothermal temperatures $T_{h}$. (a) HZFO-160; (b) HZFO-180; (c) HZFO-200.

Fig. 4 Typical TEM images of HZFO nanopowders obtained at different hydrothermal temperatures $T_{h}$. (a) HZFO-160; (b) HZFO-180; (c) HZFO-200.

Fig. 5 EDS mapping results of a typical area in HZFO-200.

Fig. 6 The XRD pattern (a), the typical SEM image (b) and the EDS mapping images of a typical area (c) in CZFO-750.

Fig. 7 The room-temperature magnetic hysteresis loops of HZFO and CZFO-750 specimens.

Fig. 8 XPS spectra and the fitted curves of two typical specimens HZFO-200 (a, c, e) and CZFO-750 (b, d, f). 


\section{Tables}

Table 1: The Fe/Zn atomic ratio $\left(R_{a}\right)$ of ZFO measured by using ICP

\begin{tabular}{ccccc}
\hline Specimens & HZFO-160 & HZFO-180 & HZFO-200 & CZFO-750 \\
\hline$R_{a}$ & 2.143 & 2.148 & 2.139 & 1.984 \\
\hline
\end{tabular}

Table 2: The binding energy (BE, eV) of Zn, Fe ions in HZFO-200 and CZFO-750.

\begin{tabular}{|c|c|c|c|c|c|c|c|}
\hline \multicolumn{2}{|c|}{ Specimens } & \multicolumn{3}{|c|}{ HZFO-200 } & \multicolumn{3}{|c|}{ CZFO-750 } \\
\hline & $\mathrm{BE}$ & Tet (A) & Oct (B) & Sat & Tet (A) & Oct (B) & Sat \\
\hline \multirow{3}{*}{$\mathrm{Zn}$} & $2 \mathrm{p} 1 / 2$ & 1044.11 & 1045.04 & & 1044.15 & 1044.75 & \\
\hline & & & & & & & \\
\hline & $2 \mathrm{p} 3 / 2$ & 1020.99 & 1021.68 & & 1020.83 & 1021.70 & \\
\hline \multirow{3}{*}{$\mathrm{Fe}$} & $2 \mathrm{p} 1 / 2$ & 726.52 & 724.37 & 732.06 & 727.04 & 724.65 & 732.43 \\
\hline & $2 \mathrm{p} 3 / 2$ & 712.66 & 710.70 & 719.32 & 712.46 & 710.68 & 719.47 \\
\hline & $3 p$ & 56.64 & 55.64 & & 57.13 & 55.76 & \\
\hline
\end{tabular}


Figures

Fig. 1

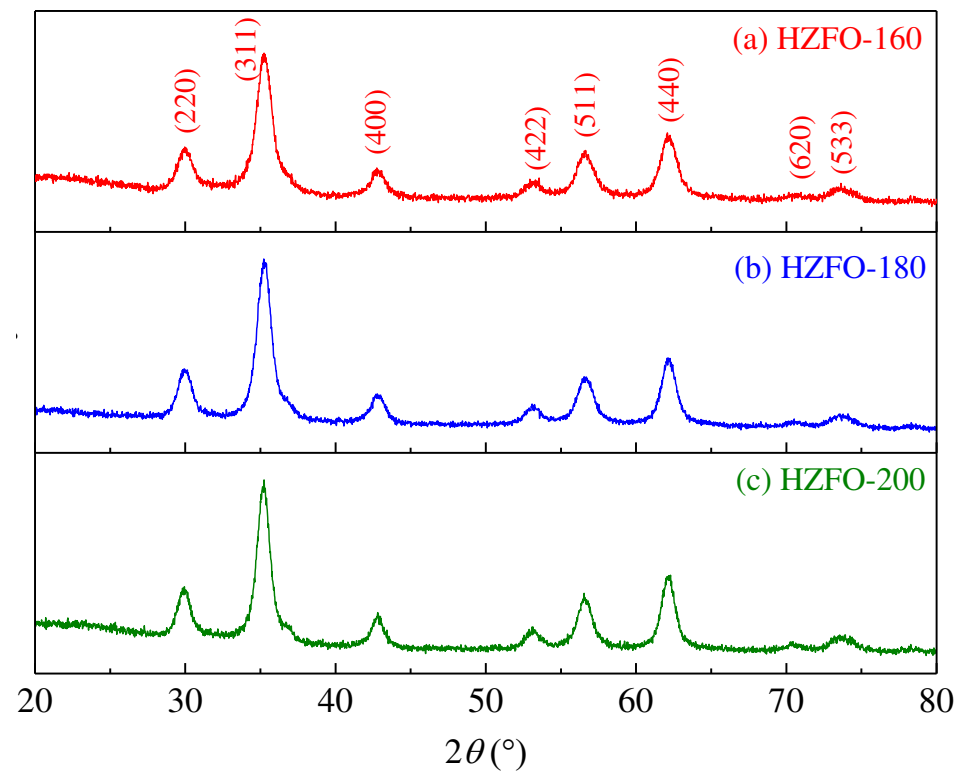


Fig. 2

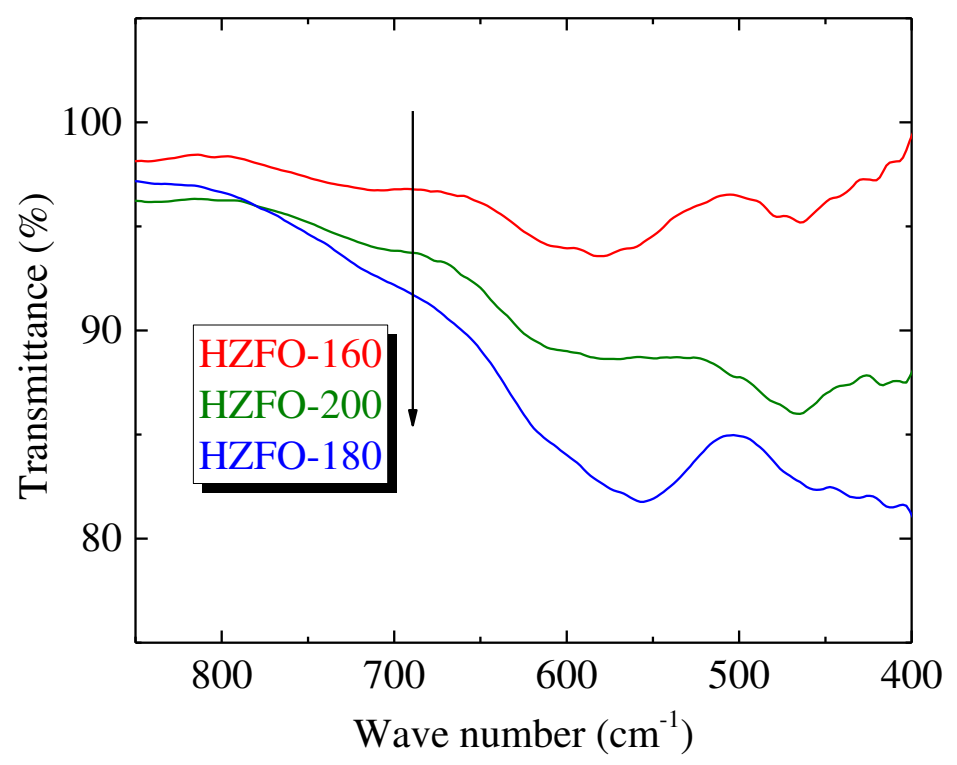


Fig. 3

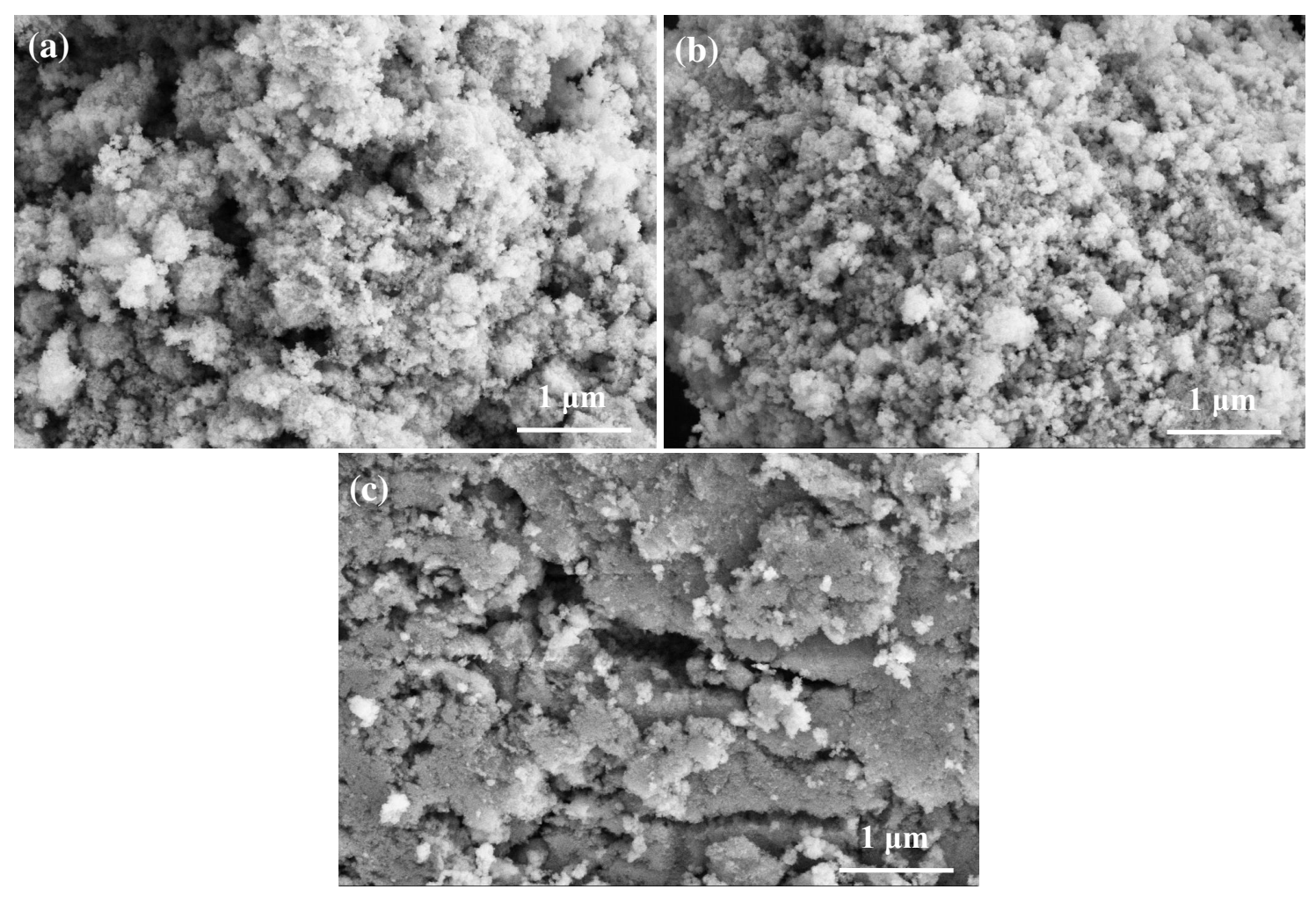


Fig. 4
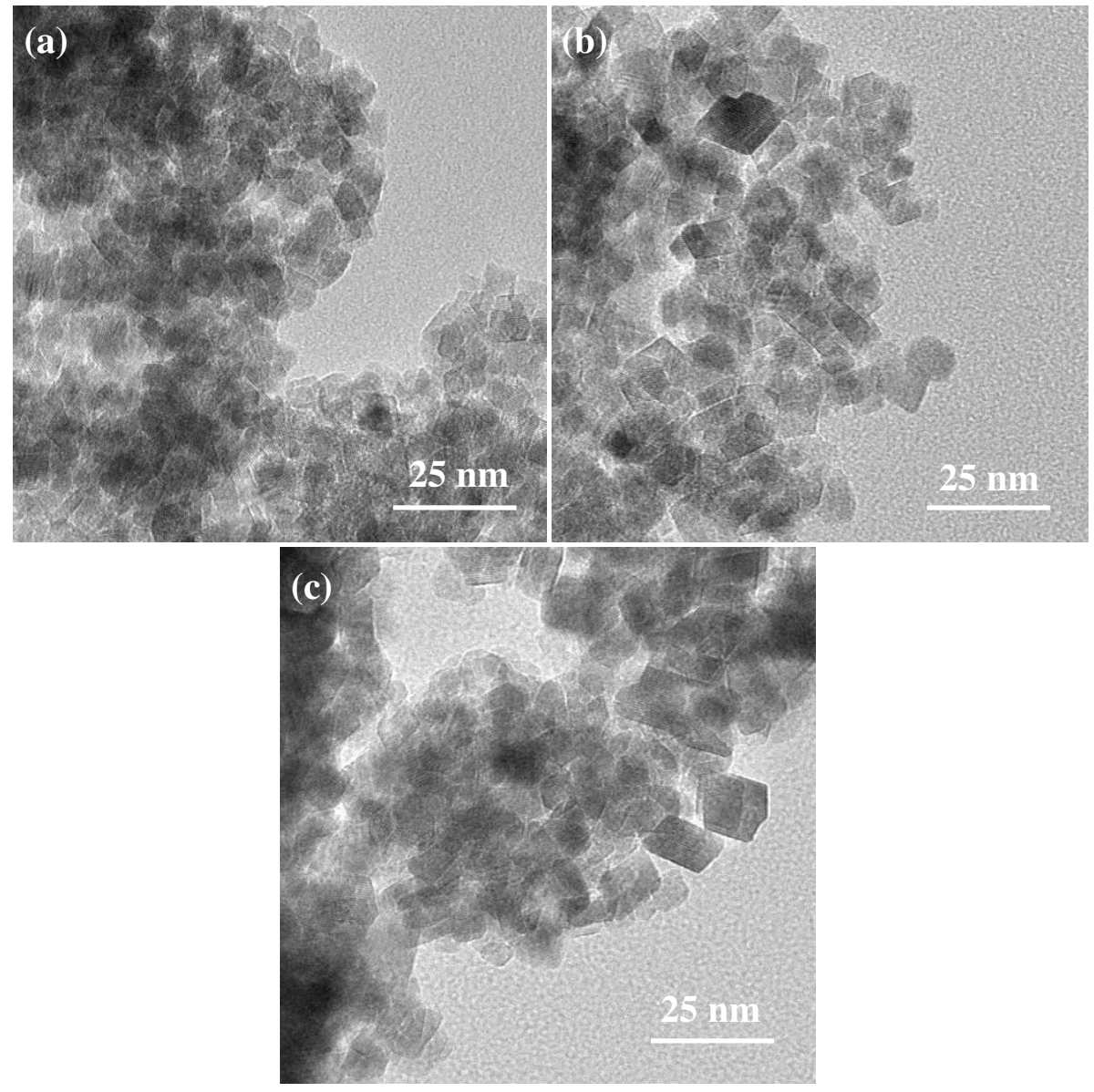
Fig. 5

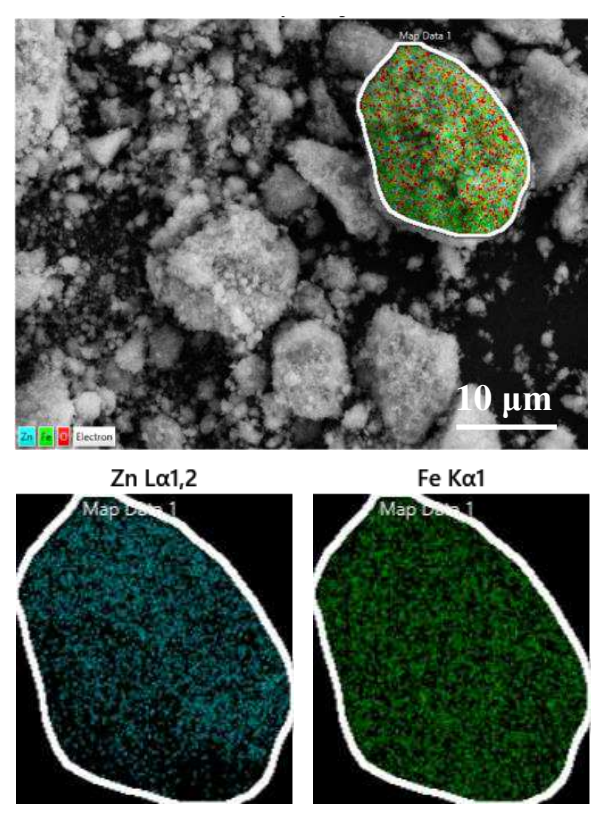


Fig. 6
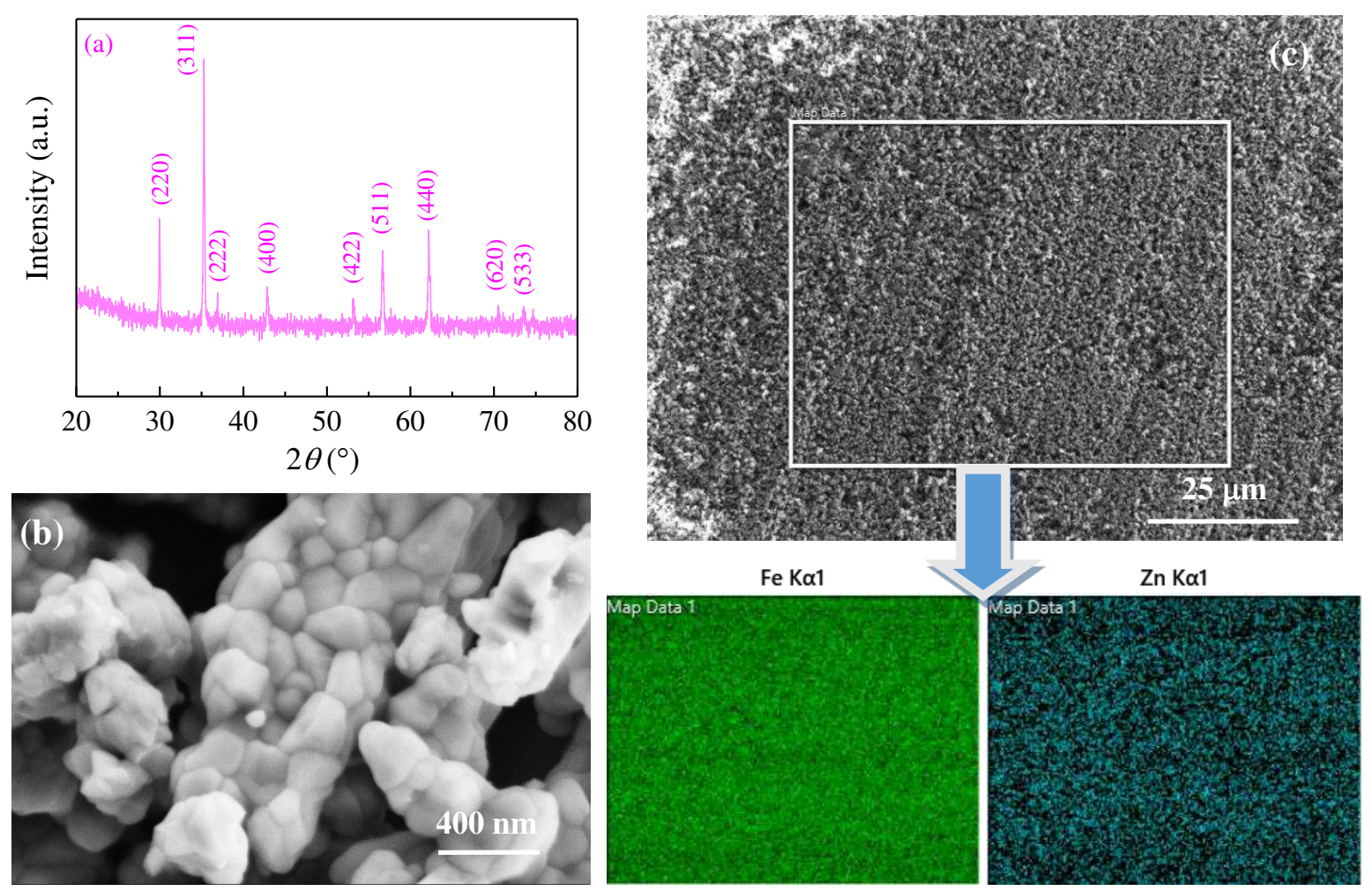
Fig. 7

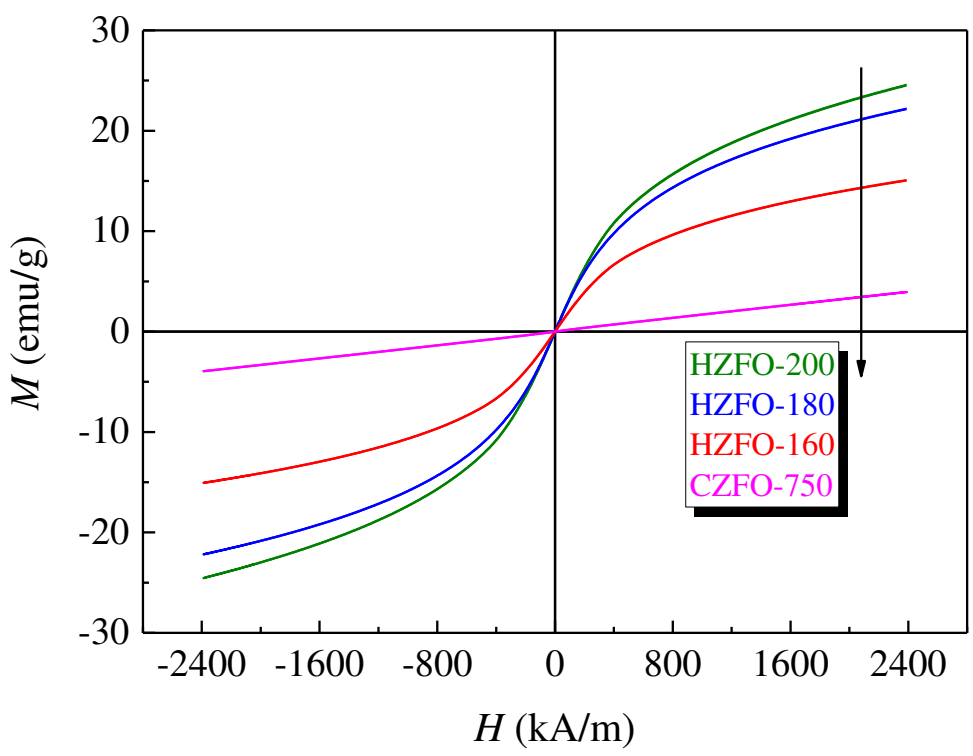


Fig. 8
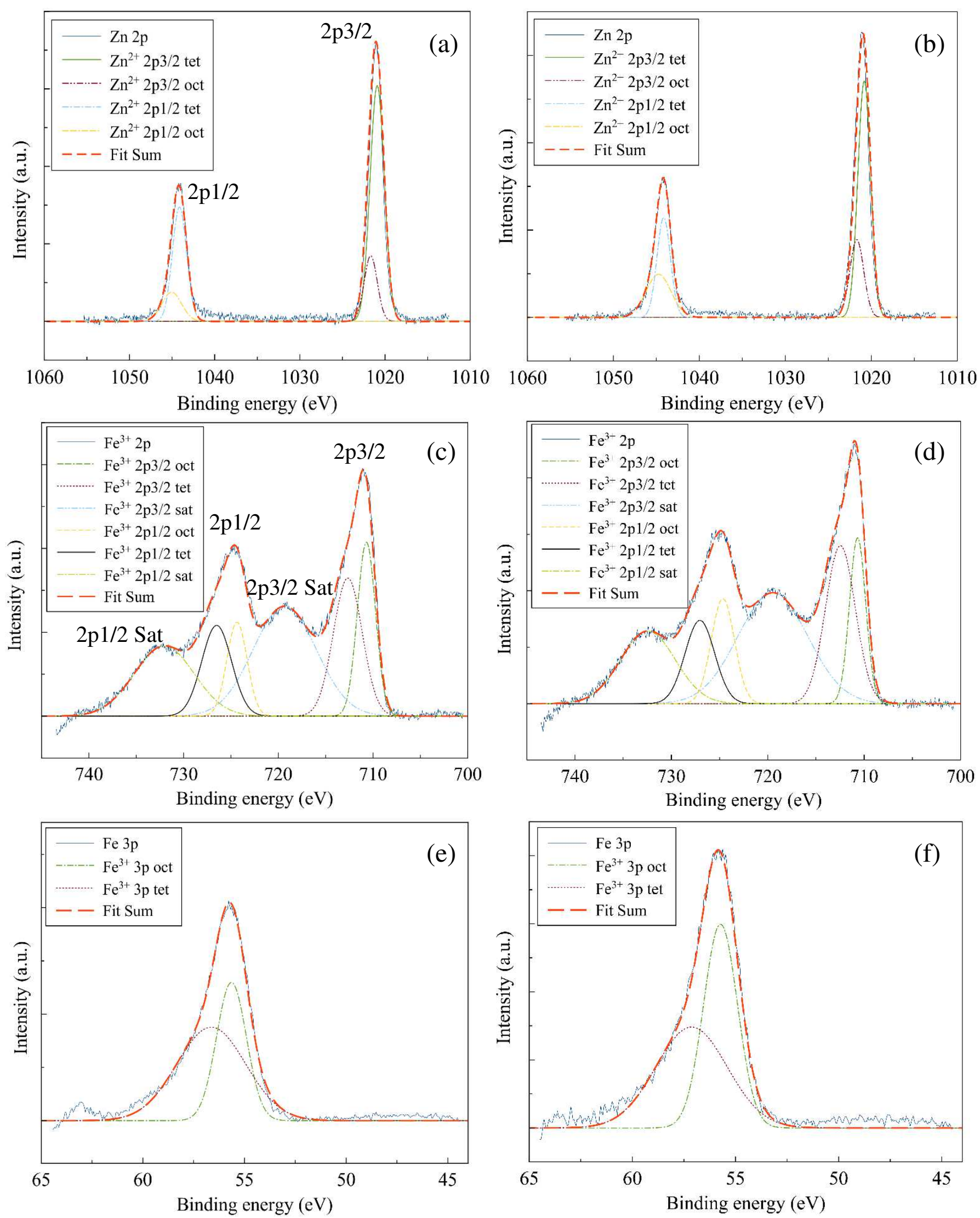
Figures

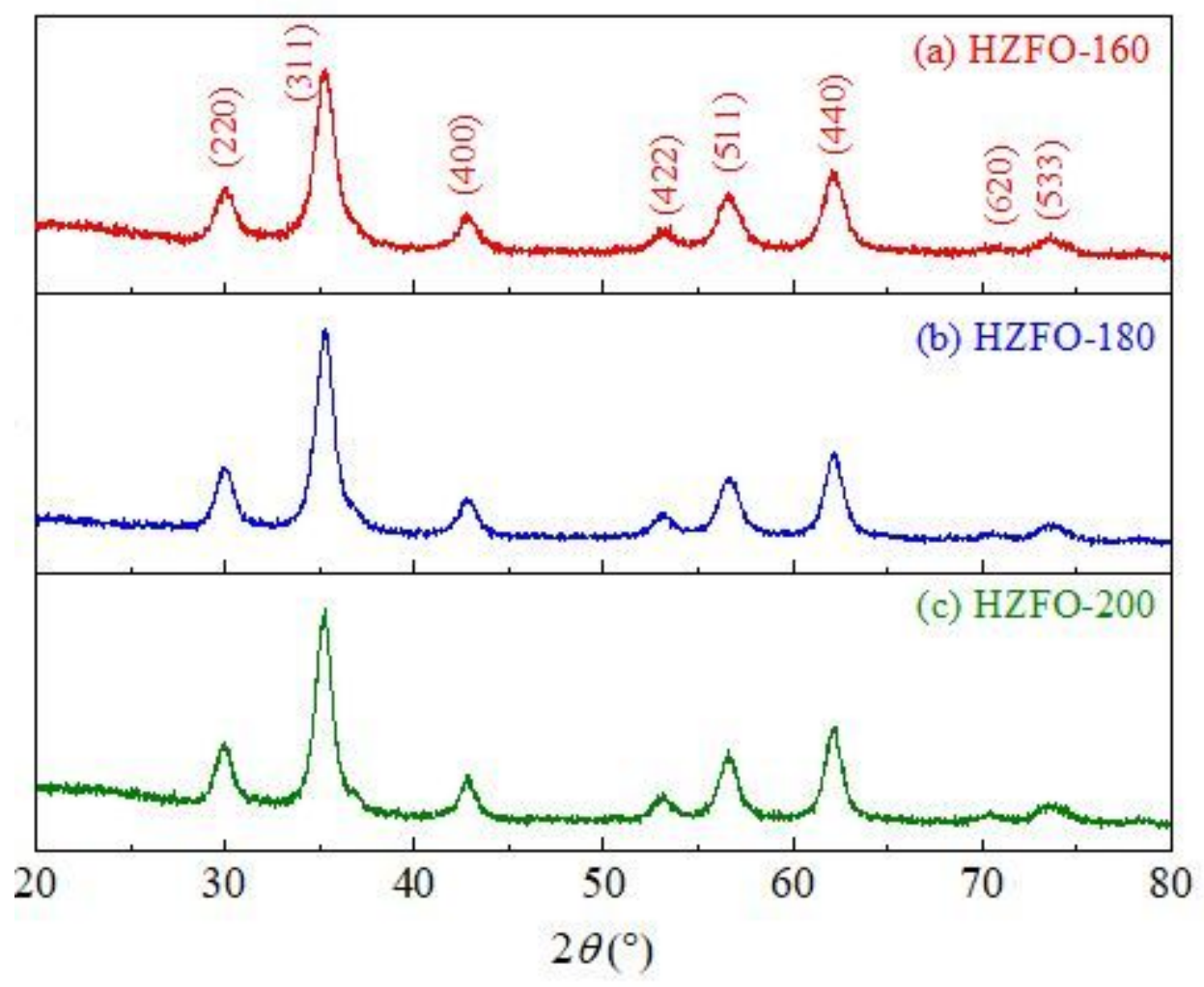

Figure 1

XRD patterns of HZFO specimens obtained at different hydrothermal temperatures Th.

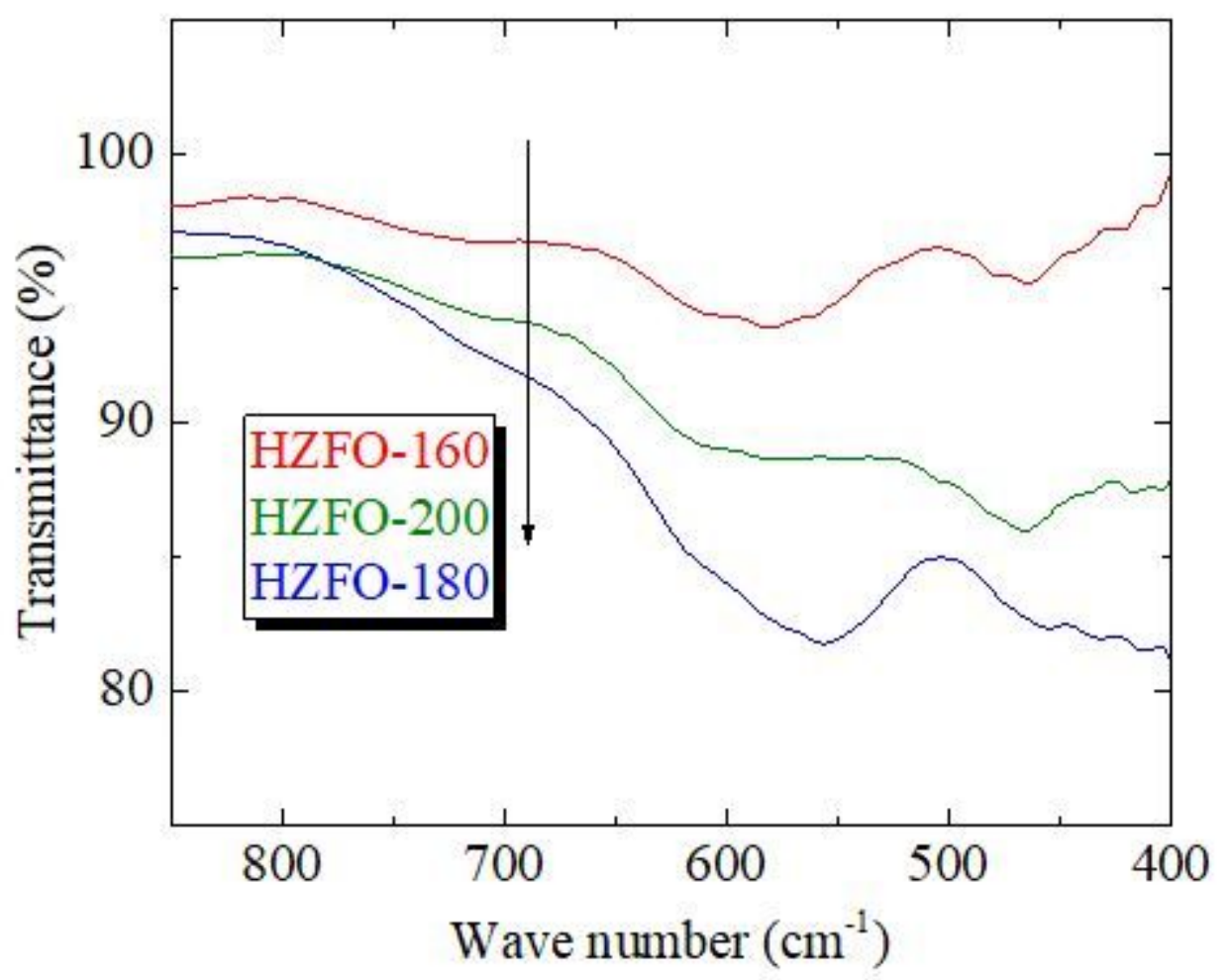


Figure 2

FTIR spectra of HZFO specimens obtained at different hydrothermal temperatures Th.
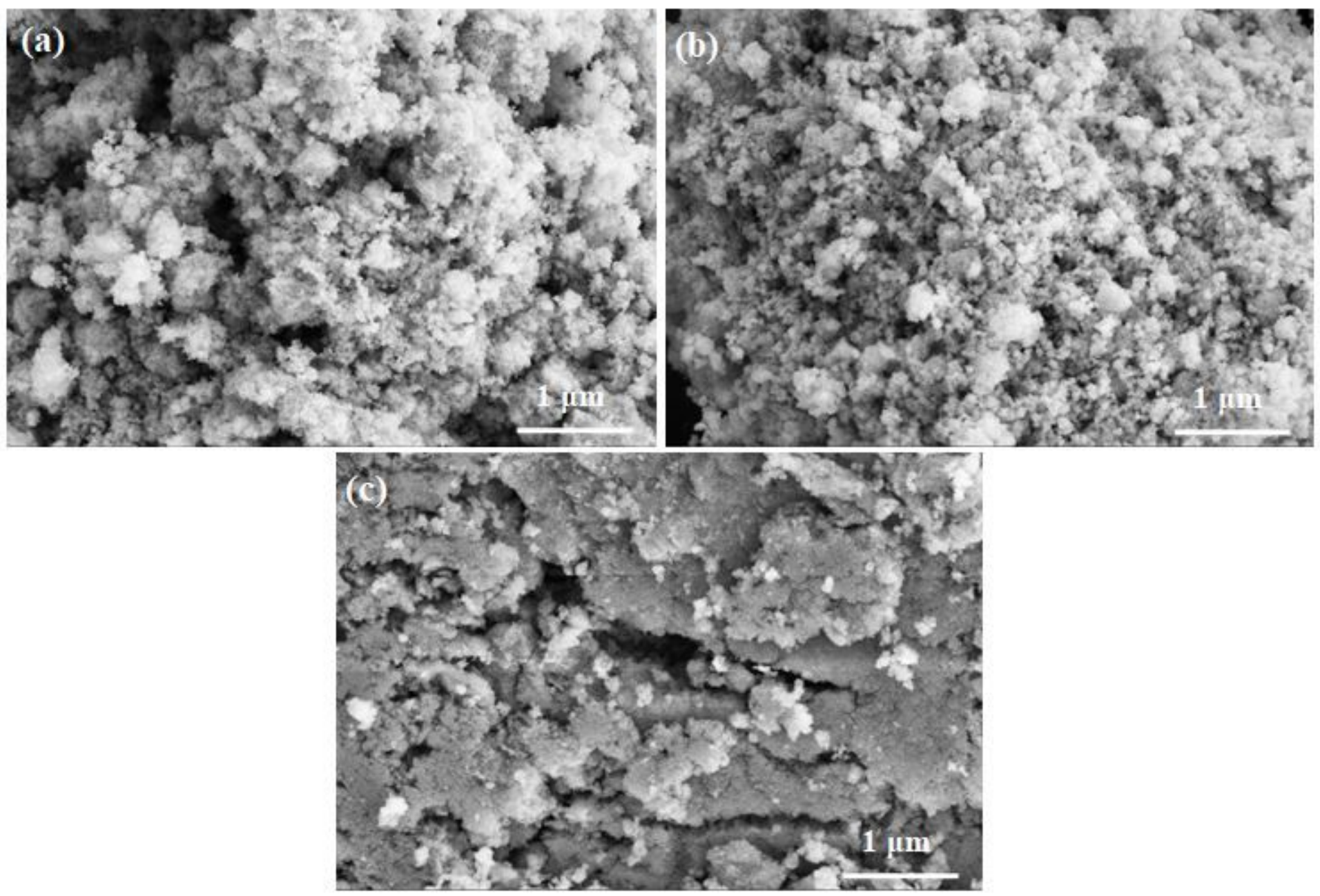

\section{Figure 3}

Typical FESEM images of HZFO specimens obtained at different hydrothermal temperatures Th. (a) HZFO-160; (b) HZFO-180; (c) HZFO-200. 

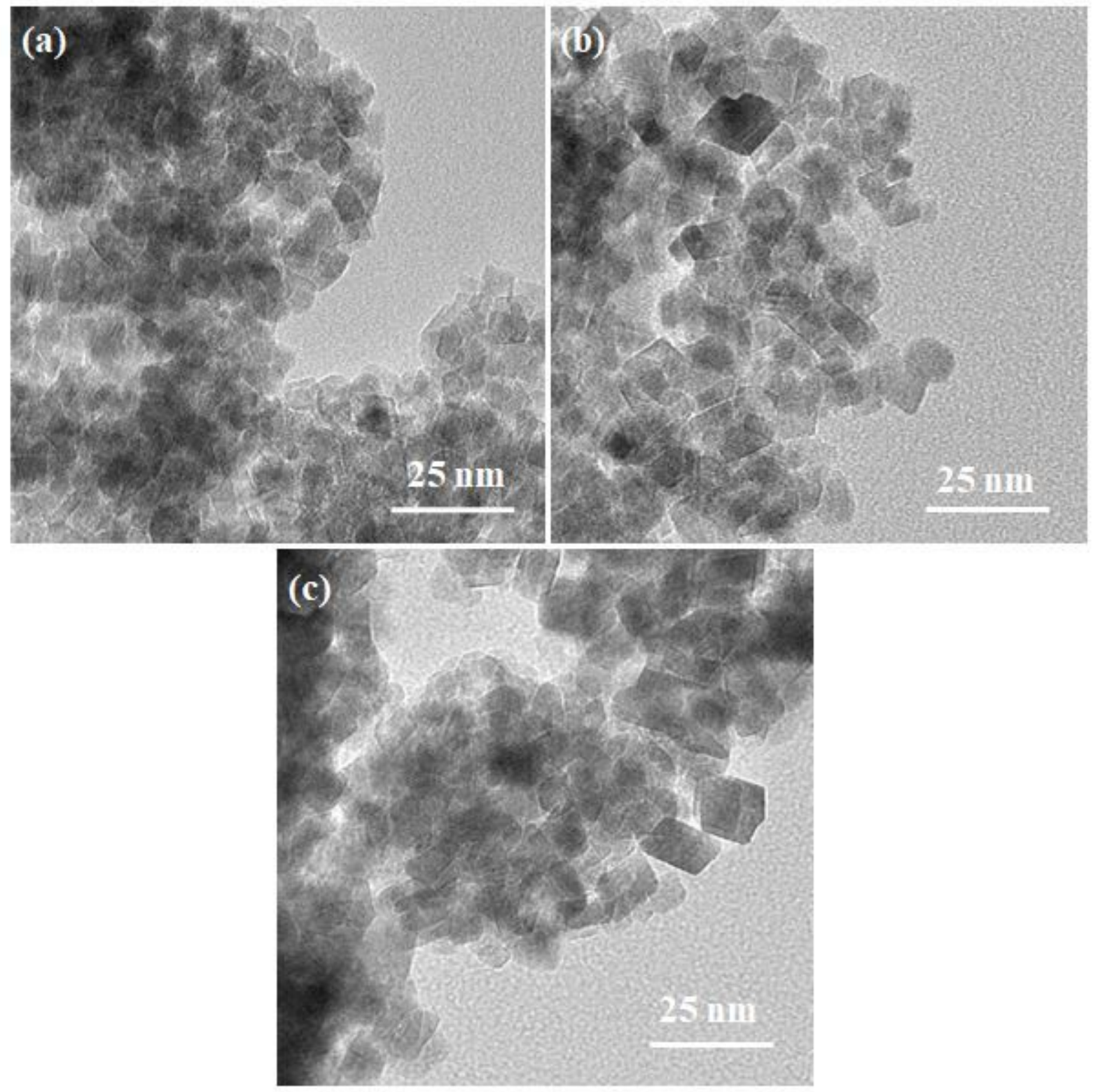

\section{Figure 4}

Typical TEM images of HZFO nanopowders obtained at different hydrothermal temperatures Th. (a) HZFO-160; (b) HZFO-180; (c) HZFO-200. 

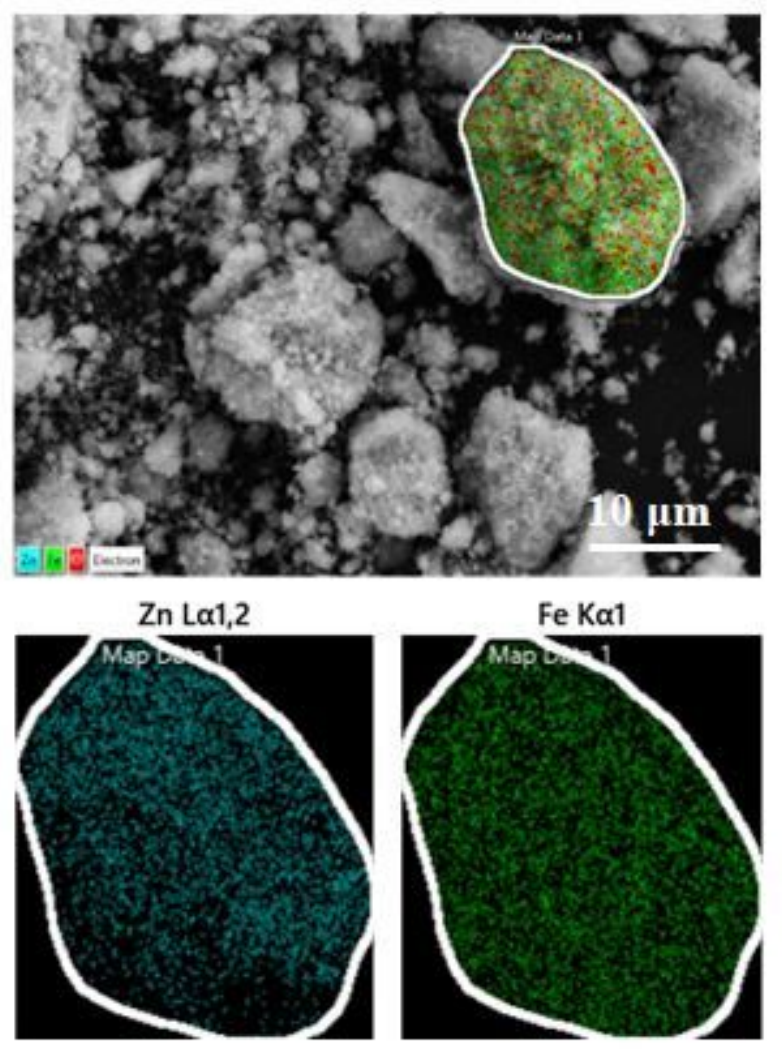

Figure 5

EDS mapping results of a typical area in HZFO-200. 

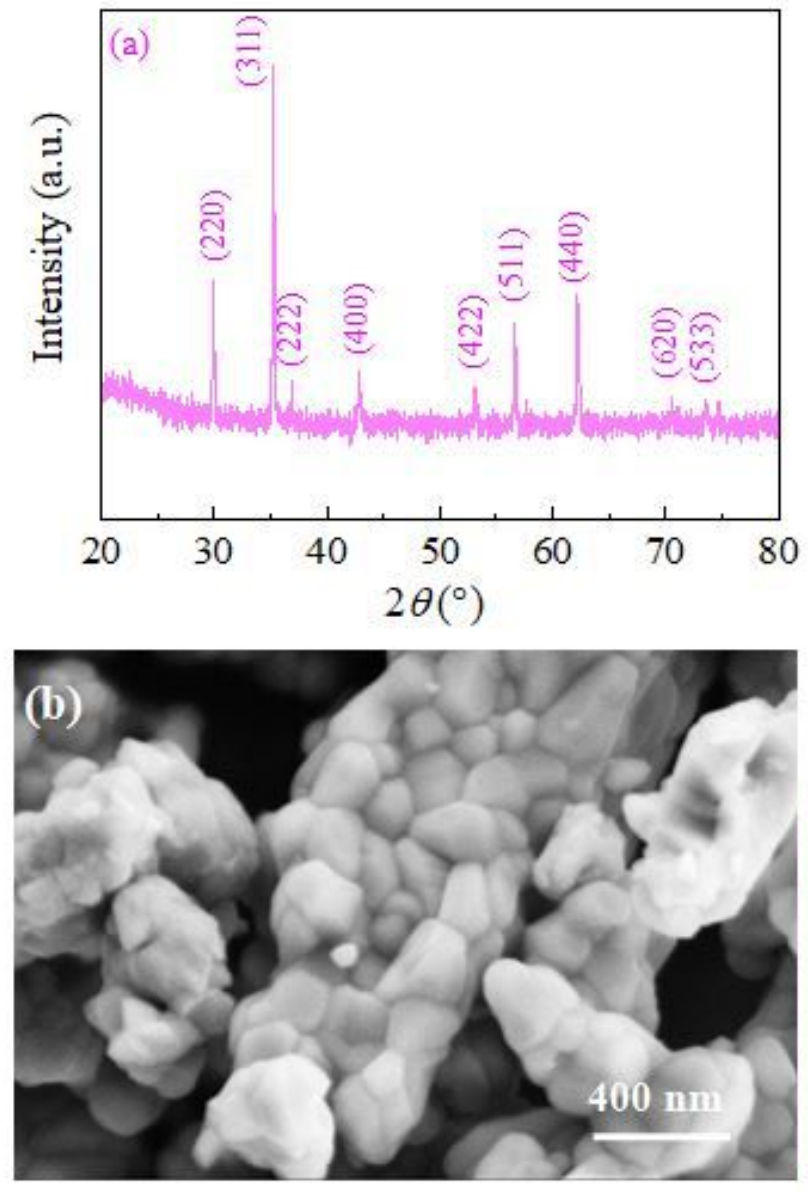

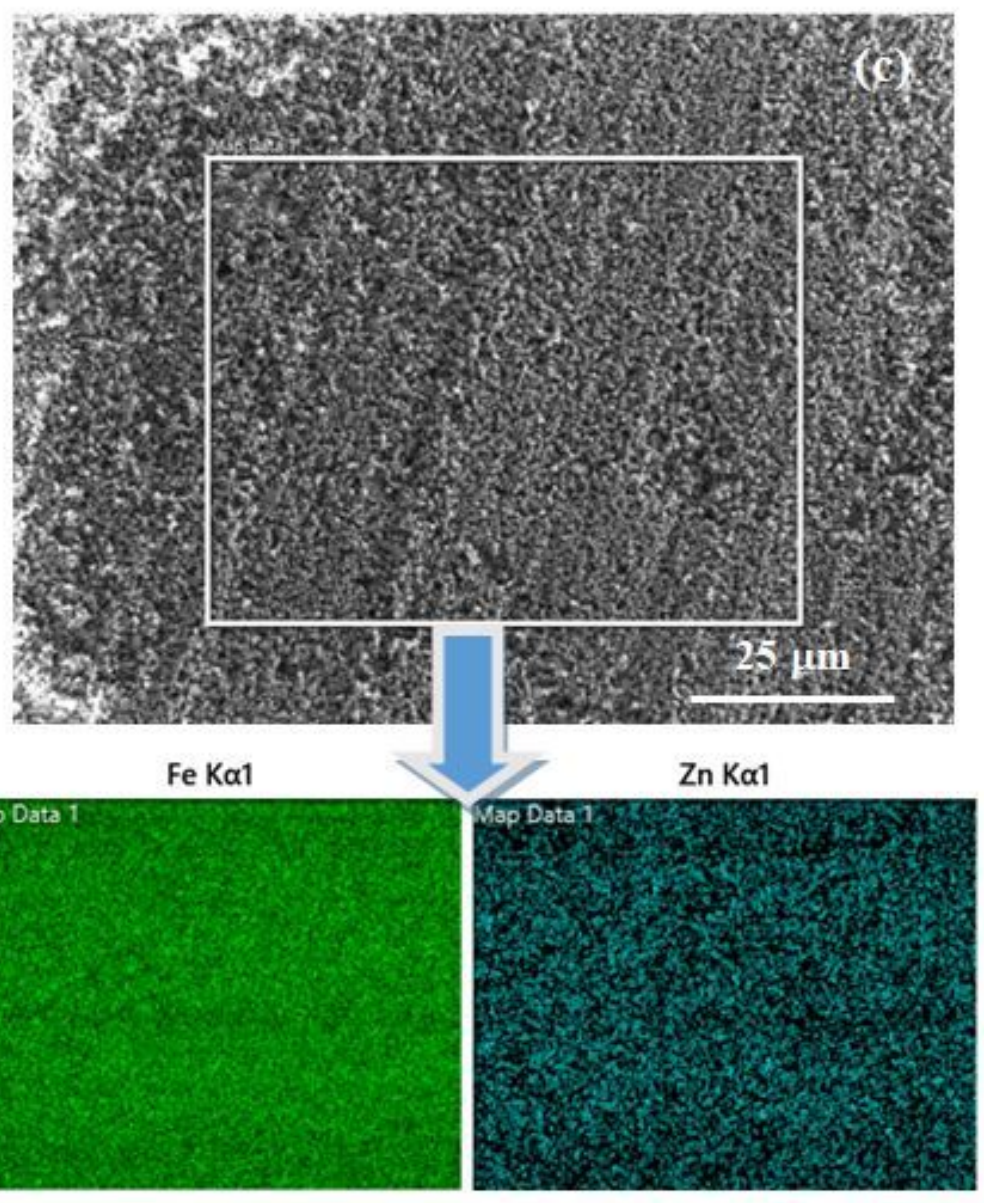

\section{Figure 6}

The XRD pattern (a), the typical SEM image (b) and the EDS mapping images of a typical area (c) in CZFO-750. 


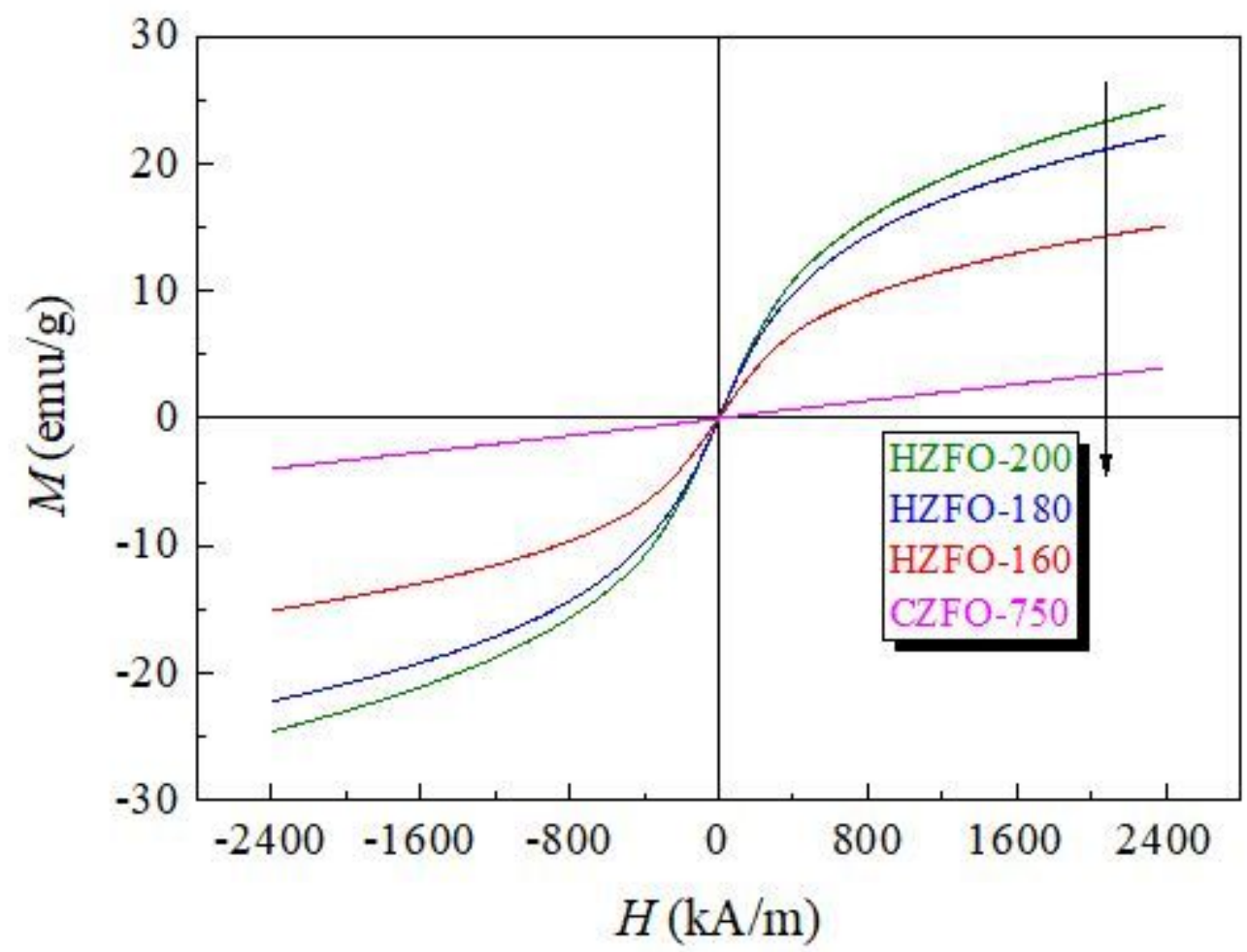

Figure 7

The room-temperature magnetic hysteresis loops of HZFO and CZFO-750 specimens.
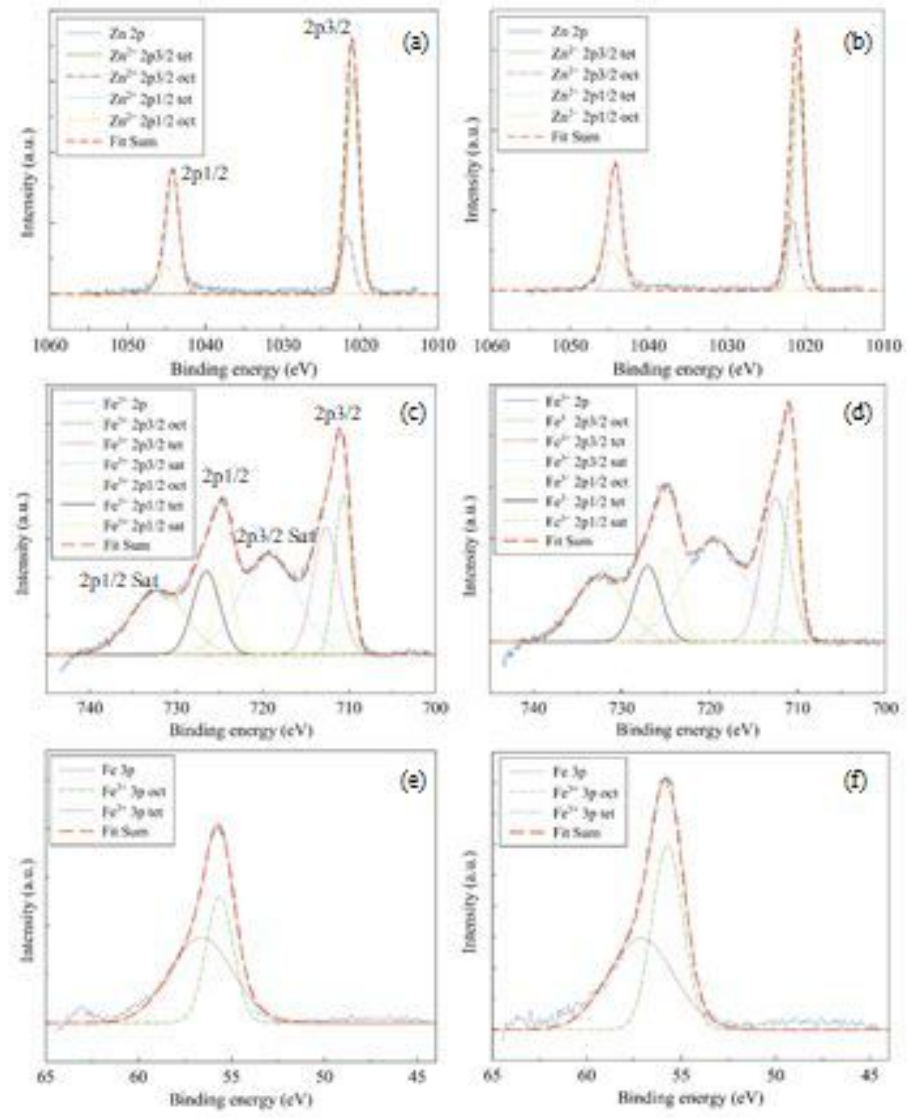

Figure 8 
XPS spectra and the fitted curves of two typical specimens HZFO-200 (a, c, e) and CZFO-750 (b, d, f). 